\title{
Research of Novel Water Cooling Jacket for Explosion-proof Motor
}

\author{
Yu Wang *, Huiming He *, and Baodong Bai*
}

\begin{abstract}
The well tightness of the coal mining water-cooling explosion-proof motor results in difficult heat dissipation, high hydraulic pressure is needed to increase the cooling effect. However, high hydraulic pressure may lead motor shell to deform, which makes it difficult to change the motor and maintain the motor unit. The method of adding keyhole caulk weld spots on the outer cooling water jacket was proposed to solve the problem. Based on the elasticity mechanics equations and the principle of finite element method the stresses and the deformations of the traditional and novel outer cooling water jacket were calculated separately. A hydraulic pressure experiment of the both cooling water jackets was constructed. Obviously, the stress and the deformation of the novel cooling water jacket are lower. The experimental result is consistent with the simulation results. It is effective to reduce the stress and the deformation of the cooling water jacket by adding the keyhole caulk weld spots.
\end{abstract}

Keywords: Finite element analyses, Cooling system, Deformation, Stress analysis, Flameproof

\section{Introduction}

The commonly used cooling structure of mining explosion-proof induction motor includes air cooling structure and water cooling structure. The water cooling structure is more safety and reliability operated in the environment of high temperature, plentiful dust and easy explosion. Shell water cooling structure for mining explosion-proof motor is a kind of ideal structure [1]-[2]. With increasing of power and decreasing of volume, the electromagnetic loads selection in the calculation of electromagnetic scheme becomes higher, which is bound to make motor heating increase.so hydraulic pressure should be increased to take the surplus heat away. If there are really high water pressures, it is vulnerable to deformation, although the hydraulic pressure experiment has been done. The motor cannot be drawn out from the motor unit because of deformation of its water jacket under high hydraulic pressure, which makes it difficult to change the motor and maintain the motor unit. Water jacket of mining explosion-proof motor is thinner and lower strength because of the dimensional limit.

Finite element method (FEM) is the classical method to solve the problems of elastic mechanics, which can structure accurate model by being used in virtual technology through parameter adjustment [3]-[4]. Linear

* School of Electric Engineering, Shenyang University of Technology, China. (electricalwangyu@163.com)

Received 15 August 2013; Accepted 10 October 2013 static analysis based on finite element method can be used to calculate the stress of motor cooling structure [5]-[7]. In conclusion, stress of traditional water jacket and novel water jacket were calculated separately under the $4.5 \mathrm{Mpa}$ hydraulic press.

In the view of the above questions, based on the finite element method "the linear static analysis" was used to calculate the motor cooling structure stress. New external water jacket structure was developed, which avoid deformation of outer water jacket.

\section{Basic Model of Strain Space Problems}

\subsection{Geometrical Equation of Spatial Strain Problems}

Take a little point $\mathrm{P}$ in the elastic body and make a micro

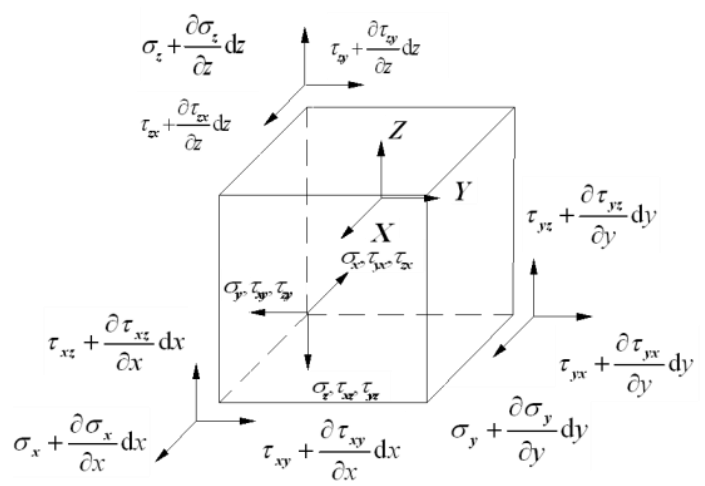

Fig. 1. Force analysis of element 
regular hexahedron at this point showed in Fig. 1. The length of micro line segments along $\mathrm{x}, \mathrm{y}$ and $\mathrm{z}$ are separately $\mathrm{dx}$, dy and $\mathrm{dz}$. $\mathrm{X}, \mathrm{Y}, \mathrm{Z}$ is uniform distribution body force on elastic body along xyz. $\sigma_{\mathrm{x}}, \sigma_{\mathrm{y}}, \sigma_{\mathrm{z}}$ is Normal stress in $\mathrm{x} \mathrm{y} \mathrm{z}$ direction. $\tau_{\mathrm{xy}}$ is shear stress on $\mathrm{x}=\mathrm{o}$ plane in $\mathrm{y}$ direction as the same as $\tau_{\mathrm{xy}}, \tau_{\mathrm{yz}}$.

Based on the static equilibrium relations, $\sum \mathrm{X}=0, \sum \mathrm{Y}=0$ and $\sum Z=0$. Equilibrium differential equations for the strain space problem are showed in (1) and (2).

$$
\left.\begin{array}{r}
\frac{\partial \sigma_{\mathrm{x}}}{\partial x}+\frac{\partial \tau_{\mathrm{yz}}}{\partial y}+\frac{\partial \tau_{\mathrm{zx}}}{\partial z}+X=0 \\
\frac{\partial \tau_{\mathrm{xy}}}{\partial x}+\frac{\partial \sigma_{\mathrm{y}}}{\partial y}+\frac{\partial \tau_{\mathrm{zy}}}{\partial z}+Y=0 \\
\frac{\partial \tau_{\mathrm{xz}}}{\partial x}+\frac{\partial \tau_{\mathrm{xz}}}{\partial y}+\frac{\partial \sigma_{\mathrm{z}}}{\partial z}+Z=0 \\
\varepsilon_{\mathrm{x}}=\frac{\partial u}{\partial x}, \gamma_{\mathrm{xy}}=\frac{\partial u}{\partial y}+\frac{\partial v}{\partial x} \\
\varepsilon_{\mathrm{y}}=\frac{\partial u}{\partial y}, \gamma_{\mathrm{yz}}=\frac{\partial v}{\partial z}+\frac{\partial w}{\partial y} \\
\varepsilon_{\mathrm{z}}=\frac{\partial w}{\partial z}, \gamma_{\mathrm{zx}}=\frac{\partial u}{\partial z}+\frac{\partial w}{\partial x}
\end{array}\right\}
$$

where, $\varepsilon_{\mathrm{x}}, \varepsilon_{\mathrm{y}}, \varepsilon_{\mathrm{z}}$ is normal strain in $\mathrm{x} \mathrm{y} \mathrm{z}$ direction, $\gamma_{\mathrm{xy}}$ is shearing strain of the XOY plane as the same as $\gamma_{\mathrm{yz}}, \gamma_{\mathrm{zx}}$.

\subsection{Physical Equation of Strain Problems}

Based on the generalized Hooke's law of mechanics of materials:

$$
\left.\begin{array}{l}
\varepsilon_{\mathrm{x}}=\frac{1}{E}\left[\sigma_{\mathrm{x}}-\mu\left(\sigma_{\mathrm{y}}+\sigma_{\mathrm{z}}\right)\right], \gamma_{\mathrm{xy}}=\frac{\tau_{\mathrm{xy}}}{G} \\
\varepsilon_{\mathrm{y}}=\frac{1}{E}\left[\sigma_{\mathrm{y}}-\mu\left(\sigma_{\mathrm{x}}+\sigma_{\mathrm{z}}\right)\right], \gamma_{\mathrm{yz}}=\frac{\tau_{\mathrm{yz}}}{G} \\
\varepsilon_{\mathrm{z}}=\frac{1}{E}\left[\sigma_{\mathrm{z}}-\mu\left(\sigma_{\mathrm{x}}+\sigma_{\mathrm{y}}\right)\right], \gamma_{\mathrm{xz}}=\frac{\tau_{\mathrm{xz}}}{G}
\end{array}\right\}
$$

where, $E$ is the elastic modulus, $G$ is the shear modulus, $\mu$ is the Poisson's ratio.

\subsection{Boundary Conditions}

Give the displacement components of constraint on the boundary $\mathrm{S}$.

It is fixed boundary according to the characteristics of the analysis model, the boundary displacement function should satisfy the (4).

$$
\left.\begin{array}{l}
(u)_{\mathrm{s}}=0 \\
(v)_{\mathrm{s}}=0 \\
(w)_{\mathrm{s}}=0
\end{array}\right\}
$$

\section{Water Jacket Structure of Mining Explosion- Proof Induction Motor}

\subsection{Traditional Structure Water Jacket}

In the traditional processing of cooling water-jacket, the inner water jacket is lathed initially, baffling reinforcements are uniformly welded on the specific location to make the cooling water flow as required, whose quantity is 12 16 and the installed and welded water jacket is lathed to the required outer diameter. The outer water jacket that is interference fitted to the inner water jacket. Positioning on the seam allowance of one end, the outer water jacket is installed out of the inner water jacket by the hot charging. The motor structure and the cooling water jacket are separately showed in Fig. 2 and Fig. 3.

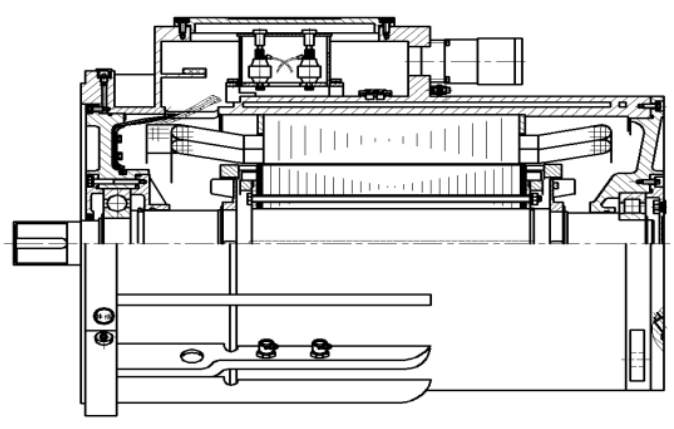

Fig. 2. Diagram of the motor structure

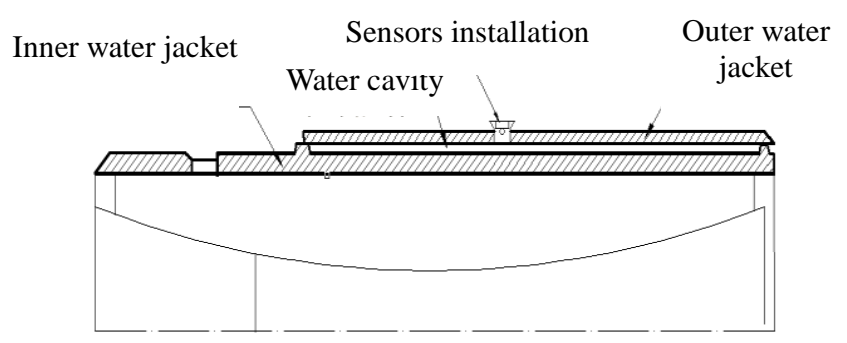

Fig. 3. Diagram of the cooling water jacket

The contact area between inner water jacket and stator iron is larger. So the strength of the inner water jacket is good. While there is no structure restrain in the outer water jacket. Consequently if the hydraulic pressure is too high or the strength of water jacket is too low when the motor operates the outer water jacket easily deform under the influence of hydraulic pressure. 


\subsection{Novel Structure Water Jacket}

In order to avoid deformation of the water jacket, the novel structure is developed. Several rows of uniformly distributed holes are processed on the coincident position between baffling reinforcements and the outer jacket. After the outer water jacket is installed out of the inner water jacket by the hot charging, the holds are firm welded to the out water jacket, showed in Fig. 4.

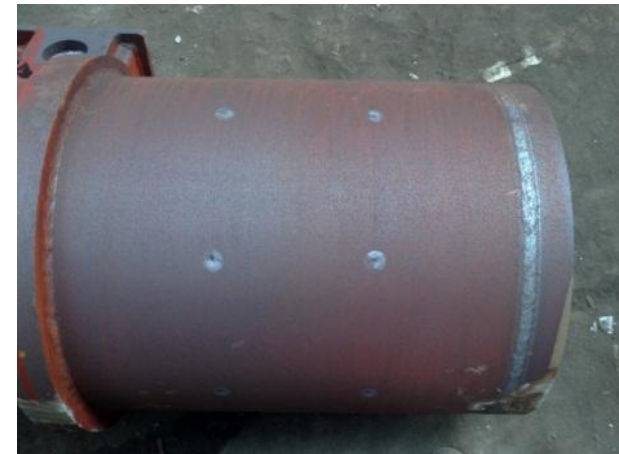

Fig. 4. The novel cooling water jacket with key hold caulks weld spots

According to the force analysis of the outer cooling water jacket showed in Fig. 5,

$$
\begin{aligned}
& -R_{\mathrm{A}} x+q x \cdot \frac{x}{2}+M(x)=0 \\
& M(x)=\frac{q l}{2} x-\frac{q}{2} x^{2}
\end{aligned}
$$

in which, $\mathrm{M}(\mathrm{x})$ is bending moment of the position $\mathrm{x}$ away from the left end, $q$ is uniformly distributed load, $R_{A}, R_{B}$ is constraining force, 1 is the distance between fixed constraint.

It is obvious when $\mathrm{x}=1 / 2$ the bending moment is maximums, $\mathrm{M}=\mathrm{ql}^{2} / 4$. So when 1 reduces the deformation of water jacket reduces. In the traditional water jacket structure $\mathrm{L}\left(\mathrm{L}_{\mathrm{TRA}}\right)$ is the axial distance of water jacket, while $\mathrm{L}\left(\mathrm{L}_{\mathrm{NOV}}\right)$ is the distance between two baffling reinforcements or two key hold caulks weld spots. It is obvious that $\mathrm{L}_{\mathrm{NOV}}$ is far more less than $\mathrm{L}_{\mathrm{TR}}$. So the maximums bending moment decreases, the deformation of novel water jacket decreases.

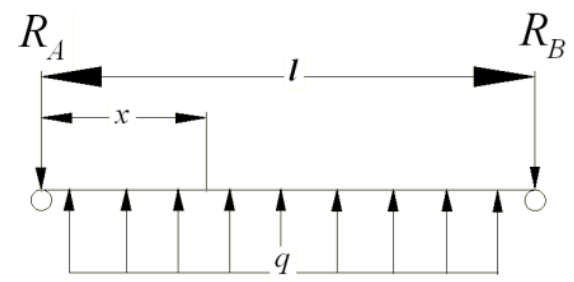

Fig. 5. Force analysis of the outer cooling water jacket

\section{Deformation Analysis of Water Jacket Based on FEM}

The simplified model of the cooling water jacket is showed in Fig. 6, the materiel of water jacket is carbon structural steel Q235-A, The physical properties of the material shows as follow: elasticity modulus is $210000 \mathrm{~N} / \mathrm{mm}^{2}$; Poisson's ratio is 0.28 ; density is $0.0078 \mathrm{~g} / \mathrm{mm}^{3}$; Yield force is $220.6 \mathrm{~N} / \mathrm{mm}^{2}$ [8]-[10].

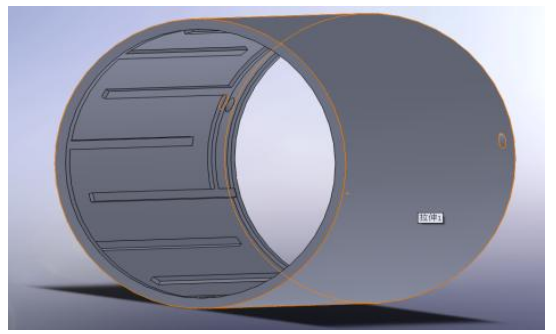

Fig. 6. Simplified model of the cooling water jacket

The inner water jacket and outer water jacket should be firmly welded at the two end faces when the water jacket installs, so the fixed restrain is imposed at the position actually welded.

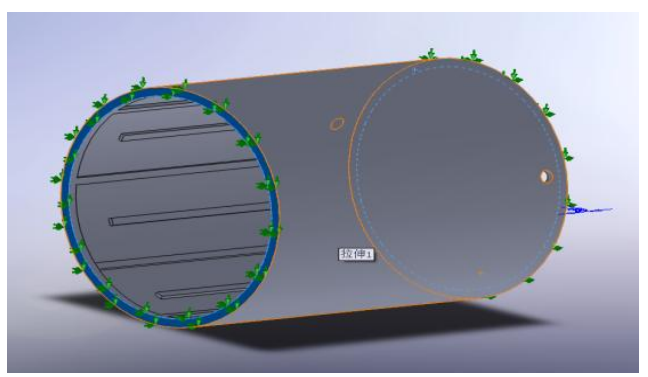

Fig. 7. Applied constraints

Working hydraulic pressure of coal mining water-cooling flameproof motor is $3 \mathrm{MPa}$ at most; $3 \mathrm{MPa}$ pressure load is imposed on the inner wall of the out water jacket. Stress cloud chart of the traditional outer cooling water jacket is obtained. It is obvious that stress of parts on water jacket are large, consequently the deformation of the water jacket is large too.

The fixed restrain is imposed at the position of keyhole caulk weld spots. Stress cloud chart of the novel outer cooling water jacket is obtained by repeating the above analysis procedure showed in Fig. 8.

It is obtained that the maximums stress of the traditional water jacket without keyhole caulk weld spots is $6.5 \mathrm{e}+7 \mathrm{~N} / \mathrm{mm}^{2}$, the maximums stress of the novel water jacket with keyhole caulk weld spots is $5.0 \mathrm{e}+7 \mathrm{~N} / \mathrm{mm}^{2}$. The maximum stress was reduced by $23.07 \%$ (Fig. 9, Fig. 10). Stress reliability has been increased significantly. The 
deformation of novel water jacket reduces obviously.

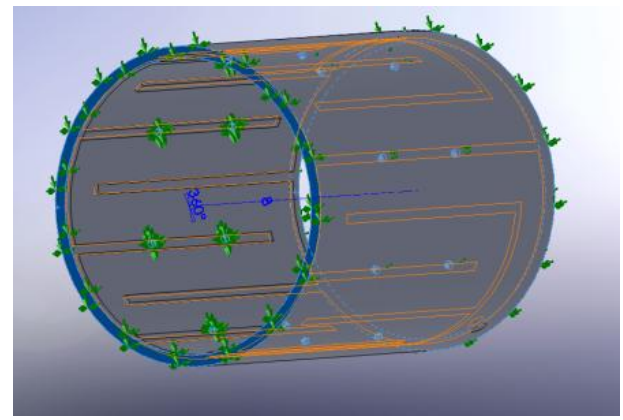

Fig. 8. Constraints distribution of the novel outer cooling water jacket

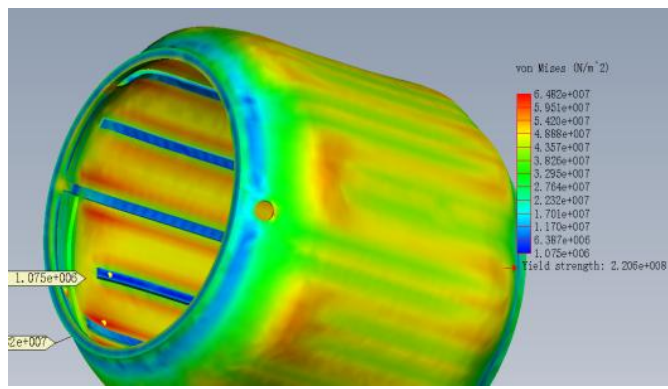

Fig. 9. Stress cloud chart of the novel outer cooling water jacket

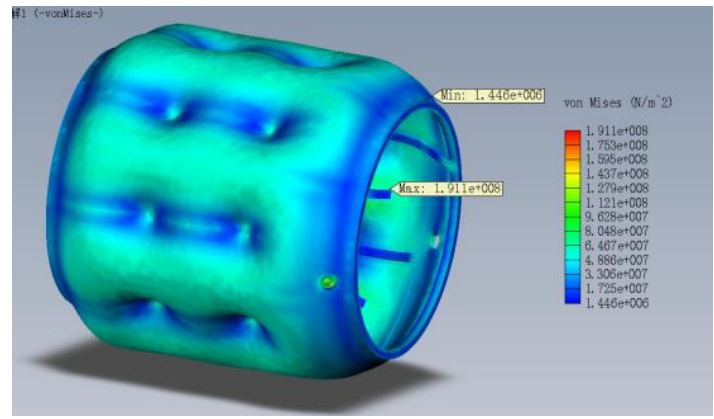

Fig. 10. Stress cloud chart of novel outer cooling water jacket

\section{Hydraulic Pressure Experiment}

The deformations of point1-6 for the novel (NOV) and traditional (TRA) water jacket are measured separately in the $5 \mathrm{MPa}$ hydraulic pressure experiment.

Table 1. Parameter of the Experimental Water Jacket

\begin{tabular}{|c|c|}
\hline Parameter & Value \\
\hline Outer Diameter & $391 \mathrm{~mm}$ \\
\hline Inner Diameter & $343 \mathrm{~mm}$ \\
\hline Water Jacket Thickness & $7 \mathrm{~mm}$ \\
\hline Height of Waterway & $10 \mathrm{~mm}$ \\
\hline Quantity of Baffle Reinforcement & 12 \\
\hline
\end{tabular}

The parameter of the experimental water jacket is showed in Table 1. Two water jackets are manufactured one with keyhole caulk weld spots the other without keyhole caulk weld spots. The 0MPa and 5MPa hydrostatic test of the two water jackets are proposed respectively. The deformation of the 6 points uniformly distributed around the water jacket circumference showed in Fig. 11 is measured. The hydraulic pressure experiment result shows that the deformation of the novel water jacket reduces $50 \%$ than the traditional one (Table.2).

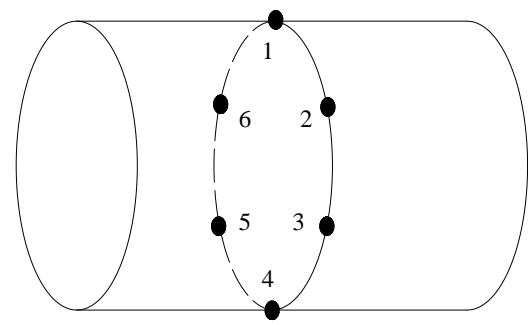

Fig. 11. Distribution of measure points

Table 2. Results of the Experiment

\begin{tabular}{|c|c|c|c|c|c|c|}
\hline Condition & \multicolumn{7}{|c|}{ Deformation (mm) } \\
\hline & 1 & 2 & 3 & 4 & 5 & 6 \\
\hline $5 \mathrm{MPa}$ Nov & 0 & 0 & 0.01 & 0 & 0.03 & 0 \\
\hline $5 \mathrm{MPa}$ Tra & 0.02 & 0.02 & 0 & 0 & 0.02 & -0.02 \\
\hline
\end{tabular}

\section{Conclusion}

This paper presents a novel water jacket with keyhole caulk weld spots. Based on the compound characteristics of the coal mining water-cooling flameproof motor the stress of the water jacket was analyzed by EMF. The calculation result shows that the maximum stress of the novel water jacket with keyhole caulk weld spots reduces $23.07 \%$ than the traditional one. Hydraulic pressure experiment result shows that the deformation of the novel one reduces $50 \%$. Water jacket strength is increased to ensure the motor cooling system stability. This kind of stress analysis method can be used as important basis for products optimizing design.

\section{References}

[1] K. Bennion, J. Cousineau. "Sensitivity analysis of traction drive motor cooling," IEEE Transportation Electrification Conference and Expo (ITEC 2012), pp. 1-6, 2012.

[2] S. Nonaka, M. Yamamoto, M.Nakano, et al, "Analysis of ventilation and cooling system for ilnduction motors," IEEE Transactions on Power Apparatus and Systems, vol. 100, no.5, pp. 4636-4643, November 1981.

[3] O.K. Bezyukov, V. A. Zhukov, O. V. Zhukova, "Effectiveness of liquid cooling systems in motors and manufacturing equipment," Russian Engineering Research, vol. 28, no. 11, pp. 1055-1057, 2008. 
[4] S. Cotin, H. Delingette, N. Ayache, "Real-time elastic deformations of soft tissues for surgery simulation," IEEE Transactions on Visualization and Computer Graphics, vol.5, no. 1, pp. 62-73, January/March 1999.

[5] D. L. James, D. K. Pai, "Accurate real time deformable objects," Proceeding In Computer Graphics (SIGGRAPH 99), pp. 65-72, 1999.

[6] J. Keller, I. Maus, G. Schlottig, et al, "Interface fracture mechanics evaluation by correlation of experiment and simulation," Electronic System-Integration Technology Conference (ESTC 2010), pp. 1-5, Sept. 2010.

[7] Q. Chao, H. Wenping, "Optimum design of cantilever bracket by using COSMOS Works," Mechanical Engineering \& Automation, vol. 4, pp. 39- 41, 2007.

[8] Zhu Baoquan, Du Jinming, Zhai Wenjie, "Finite element analysis of the contact stresses in the structure of ball head and spherical cup," Journal of Harbin Institute of Technology, vol. 43, no. 1, pp. 167-169, 2011

[9] R.A. Schapery, "Homogenized constitutive equations for linear viscoelastic unidirectional composites with growing transverse cracks," Mechanics of Time - Dependent Materials, vol. 6, no. 2, pp. 15-22, 2002.

[10] P. C. Dumir, M. L. Gandhi, Y. Nath, "Axisymmetric static and dynamic buckling of orthotropic shallow spherical caps with flexible supports," Acta Mechanica, vol.52, no.1-2, pp. 93-106, July 1984.

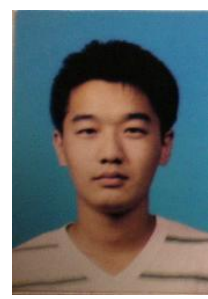

Yu Wang received the $\mathrm{BE}$ degrees in Electrical and Electronic Engineering from Shenyang University of Technology, China, in 2010. Since 2012, he has been a doctoral candidate in the Department of Electronic Engineering, Shenyang University of Technology. His research interests include design of special motors and motion control system. He is an IEEE graduate student member.

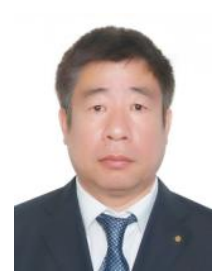

proof motor.

Huiming He received Doctor's degree in electric machines and electric apparatus from Shenyang University of Technology, and now he is a chief engineer. His research interests include key issues in the design and manufacture of the explosion-

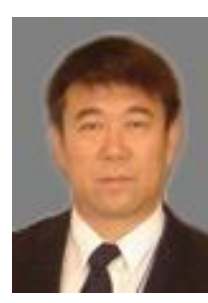

Baodong Bai received Doctor's degree in electric machines and electric apparatus from Shenyang University of Technology, and now he is a professor. His research interests include electro-magnetic fields and electromagnetic compatibility. $\mathrm{He}$ is an IEEE member. 